\title{
Dynamic Steady State by Unlimited Unidirectional Plastic Deformation of Crystalline Materials Deforming by Dislocation Glide at Low to Moderate Temperatures
}

\author{
Javier Gil Sevillano \\ TECNUN and Ceit, Technological Campus, University of Navarra, Paseo M. de Lardizabal 13, \\ 20018 San Sebastián, Spain; jgil@ceit.es
}

Received: 26 November 2019; Accepted: 23 December 2019; Published: 1 January 2020

check for updates

\begin{abstract}
This paper presents an outline of the quest for the mechanical steady state that an unlimited unidirectional plastic strain applied at low to moderate temperature is presumed to develop in single-phase crystalline materials deforming by dislocation glide, with particular emphasis on its athermal strength limit. Fifty years ago, the study of crystalline plasticity was focused on the strain range covered by tensile tests, i.e., on true strains less than unity; the canonic stress-strain behavior was the succession of stages I, II, and III, the latter supposedly leading to a steady state defining a temperature and strain rate-dependent flow stress limit. The experimentally available strain range was increased up to Von Mises equivalent strains as high as 10 by the extensive use of torsion tests or by combinations of intermittent deformations by wire drawing or rolling with tensile tests during the 1970s. The assumed exhaustion of the strain-hardening rate was not verified; new deformation stages, IV and V, were proposed, and the predicted strength limit for deformed materials was nearly doubled. Since the advent of severe plastic deformation techniques in the 1980s, such a range was still significantly augmented. Strains of the order of several hundreds were routinely reached, but former conclusions relative to the limit of the flow stress were not substantially changed. However, very recently, the plastic strain range has allegedly been expanded to $10^{5}$ true strain units by using torsion under high pressure (HPT), surprisingly for some common metals, without experimental confirmation of having reached any steady state. This overview has been motivated by the scientific and technological interest of such an open-ended story. A tentative explanation for the newly proposed ultra-severe hardening deformation stage is given.
\end{abstract}

Keywords: plastic deformation; strain hardening; deformation stages; dynamic steady state; crystalline materials; dislocation density limit

\section{Introduction}

This paper presents an overview of the quest for the mechanical steady state that an unlimited unidirectional plastic strain applied at low to moderate temperature is presumed to develop in single-phase crystalline materials which deform by dislocation glide, with particular emphasis on its athermal strength limit. An enormous research work has been undertaken on this subject during the past 50 years.

The plastic deformation of single-phase crystalline materials induces structural changes that bring about important changes of mechanical properties: strain hardening, ductility, toughness, etc. At (approximately) low to moderate homologous temperatures relative to the melting temperature

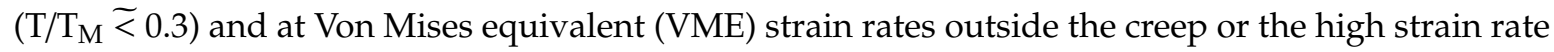
regimes $\left(10^{-5} \mathrm{~s}^{-1} \widetilde{<} \dot{\bar{\epsilon}} \widetilde{<} 10^{2} \mathrm{~s}^{-1}\right)$, the strain contribution of deformation mechanisms requiring long-range 
self-diffusion is not relevant. Deformation takes place mainly by dislocation glide on crystallographic slip systems (in some cases complemented by deformation twinning) and the VME flow stress $(\bar{\sigma})$ versus VME plastic strain $(\bar{\epsilon})$ response shows several well-known "deformation stages" (see [1-3] for reviews).

Most often, the strain-hardening rate, $\mathrm{SHR}, \bar{\theta}=\partial \bar{\sigma} / \partial \bar{\epsilon}$, steadily decreases from a transient high initial value, particularly when the starting structure is polycrystalline or in general, when the strain is resolved at the meso level by the combined activation of several non-coplanar slip systems (multiple slip). Beyond a short (in terms of strain) elastic-plastic transient, the initial stress-strain curve fits the so-called Voce equation rather well:

$$
\frac{\bar{\sigma}_{s}-\bar{\sigma}}{\bar{\sigma}_{s}-\bar{\sigma}_{0}}=\exp \left(-\frac{\bar{\theta}_{0} \cdot \bar{\varepsilon}}{\bar{\sigma}_{s}-\bar{\sigma}_{0}}\right)
$$

The three parameters of the Voce equation are an ideal elastic limit, $\bar{\sigma}_{0}$ (the back extrapolation of the flow stress to zero strain), the SHR extrapolated to zero strain, $\bar{\theta}_{0}$ and an ideal saturation flow stress that would be reached after infinite strain, $\bar{\sigma}_{s}$. This regime of deformation is identical to the so-called Stage III observed in single crystals, as will be explained below.

In the low temperature/high strain rate range of the $T-\dot{\bar{\epsilon}}$ sub-space here considered, single crystals may show another two deformation stages before Stage III. High-purity single crystals oriented for single slip show an "easy glide" Stage I of very weak SHR relative to the shear modulus $G^{*}\left(\bar{\theta}_{I} / G^{*} \approx\right.$ $3 \times 10^{-3}$ ) (shear modulus appropriate for the calculation of the dislocation line tension with account of the elastic anisotropy of the crystal). After some strain (implying crystal rotation toward multiple slip regions in orientation space), the easy-glide Stage I gives way to a new stage, Stage II, of high and constant SHR. Multicrystals, i.e., polycrystals (usually of big grain size) whose smallest physical dimension $L$ of the deforming specimen is less than about 10 times the grain size, $L<10 D$, show a composite Stage I+II before Stage III fully develops (their crystals deform under relaxed constraints relative to a grain within a true polycrystal). Stage II of single crystals is an athermal hardening stage that is not always present but always detectable as asymptotic behavior. It is followed by another strain stage of the steady decrease of SHR, Stage III. Both the transition from stages II to III and the evolution of the SHR in Stage III are dependent on T and $\dot{\bar{\epsilon}}$ (and, of course, on the material: its chemical composition, crystallographic structure, lattice friction stress level, melting temperature $T_{M}$, and stacking-fault energy, SFE, in particular).

Although it is true that such three-stage behavior is much better documented for face-centered cubic (fcc) metals of medium or high SFE than for other materials, it is typical of any crystalline materials deforming exclusively by crystallographic slip (dislocation glide) up to moderate VME strains of the order of 1 . Of course, it is masked (it becomes irrelevant) in intrinsically hard materials, i.e., materials with high values of lattice friction stress, because their work hardening weakly contributes to their flow stress.

At the microscopic level, the observed three-stage flow stress curve stems mainly from quasiathermal interactions of gliding dislocations with other gliding or stored dislocations and with grain boundaries (giving way to statistically stored dislocations, SSD) counteracted in Stage III by thermally activatable dynamic recovery mechanisms of dislocation annihilation. They are the main contributors to the SHR of stages I (from self-interactions in single glide), II of single crystals (chiefly from attractive non-coplanar interactions in multiple glide), and III of single crystals or polycrystals [4]. The interaction with grain boundaries is at the origin of strengthening by the Hall-Petch effect, mostly from the storage of geometrically necessary dislocations, GND, related with the plastic heterogeneity of neighboring grains [2,5]. Therefore, at least if one is interested in the broad picture and not (on this occasion) in the details, for understanding the flow stress-strain evolution, one must confront it with the evolution of two structural variables, the dislocation density and the grain size (setting aside the evolution of crystallographic texture, incorporated in an often weakly changing orientation factor). This will be 
the scheme followed in this paper; it turns out that revising the plastic behavior at increasing strains amounts to follow the story of this subject in chronological order.

Finally, a mention of the effect of deformation twinning on the stress-strain behavior at large strains should be given. When deformation twinning complements dislocation glide, the original grains are progressively fragmented by the boundaries separating the increasing number of twins from their grain matrix. As a result, a nearly constant SHR due to a dynamic Hall-Petch effect reinforces the dislocation density-related SHR during the strain range where deformation twinning is significant. Such behavior is blatant in the so-called TWIP steels, but it is evident in other easily twinning materials, too (hexagonal close-packed (hcp) and low SFE fcc metals and alloys) [6-8]. The TWIP regime ends when deformation twinning becomes exhausted in the highly deformed refined microstructure; then, the stress-strain returns to Stage III and other possible ensuing stages. At large strains, the effect of deformation twinning is a shift of the SHR versus the flow stress curve to the right. Figure 1 is an example of the described behavior.

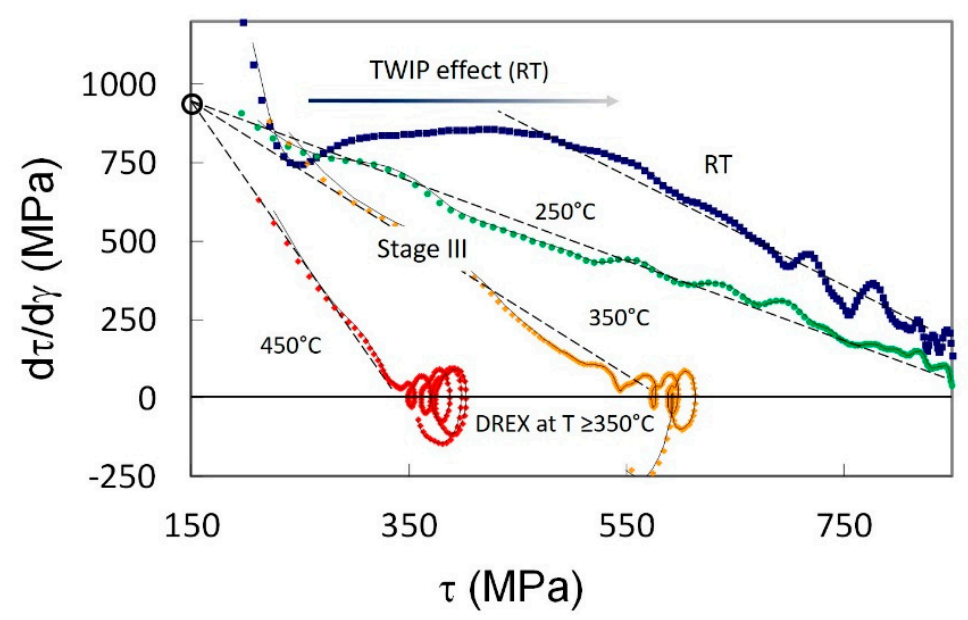

Figure 1. Fe-22\%Mn-0.6\%C twinning-induced plasticity (TWIP) steel. Strain-hardening rate (SHR) in shear vs. macroscopic shear flow stress from torsion tests at several temperatures and $1.4 \times 10^{-3} \mathrm{~s}^{-1}$ shear strain rate. At room temperature (RT), the TWIP activity starts after a short Stage III activity and produces a transient SHR increase. Deformation twinning at this strain rate is irrelevant for $\mathrm{T}>150{ }^{\circ} \mathrm{C}$. See ref. [6] for more results on this steel.

\section{Small to Moderate Plastic Strains}

In the absence of intense deformation twinning or excluding nanograin materials, the straininduced flow stress change in a single-phase material is largely governed by the strain-induced change of its statistically stored dislocation density, $\rho_{s}$, which most often represents the main fraction of the total dislocation density, $\rho$.

\subsection{Statistical Dislocation Storage}

Assume a mobile dislocation line that would glide in the absence of any activity of dynamic recovery through the three-dimensional structure of dislocation lines present in a cubic crystal volume $l_{x} l_{y} l_{z}$ with $z$ being the direction normal to the slip plane and $x$ the slip direction. Its crossing of the volume element would lead to

(a) a macroscopic finite strain increment of amount

$$
\Delta \bar{\varepsilon}=\Delta u_{x} / M l_{z}=b / M l_{z}
$$

where $b$ is the modulus of the Burgers vector of the mobile dislocation (the shear displacement increment $\left.\Delta u_{x}\right)$ and $M \approx 3$ is the texture-dependent orientation factor relating tensile strain with 
crystallographic slip shear. As deformation texture evolves the value of the orientation factor changes. However, in general, the influence of such a change is not as important as that of the other strain-induced structural changes. Reference [9] treats in detail the evolution of the orientation factor through several strain paths.

(b) an increment of the stored dislocation length per unit volume that, from geometrical reasons, scales with $\sqrt{\rho}$ (geometrical similitude implies that the dislocation length stored per unit area swept by the dislocation, $\Delta L_{S}$, is proportional to the forest dislocation density piercing the slip plane, $\rho / 2$, times a characteristic length of such density, $1 / \sqrt{\rho}$ ):

$$
\Delta \rho^{+}=l_{x} l_{y} \Delta L_{S} / l_{x} l_{y} l_{z}=\beta \sqrt{\rho} / l_{z}
$$

The scaling factor $\beta$ is independent of strain as far as the dislocation structure maintains geometrical similitude independently of $\rho[2,3]$.

Now, on account of the so-called "Taylor relationship", between dislocation density and flow stress

$$
\bar{\sigma}-\bar{\sigma}_{0}=M \alpha G^{*} b \sqrt{\rho}
$$

it is possible to derive the strain-hardening rate, SHR, in such circumstances.

In Equation (4), $\bar{\sigma}_{0}$ is the flow stress limit of the structure at zero stored dislocation density (it includes the contributions of lattice friction stress and solution strengthening, i.e., it depends on temperature and strain rate), $G^{*}$ is the shear elastic modulus at the test temperature, and $\alpha \cong 0.3$ is the quasi-athermal and quasi-universal strengthening factor of three-dimensional dislocation structures.

The macroscopic SHR for strain deprived of any dynamic recovery activity would be

$$
\bar{\theta}_{0} \cong \frac{M^{2} \alpha \beta}{2} G^{*} \approx \beta G^{*}
$$

i.e., a constant SHR as far as the assumptions made are valid, which is in good agreement with experimental findings.

In fact, this is not quite true: the factor $\alpha$ in the Taylor equation slightly depends (through a logarithmic factor) on the dislocation density (it visibly decreases as the dislocation density increases by several orders of magnitude). Similarly, $\alpha$ is mildly sensitive to the spatial distribution of local dislocation density that changes from near-uniform to cellular to subgranular as plastic strain goes on, increasing in that order [2]. Thus, the two effects somewhat compensate each other, and Equation (5) is an acceptable approximation.

The storage parameter $\beta$ also depends on the spatial distribution of the local dislocation density, as stated above, and plastic deformation does not strictly maintain structural similitude (as strain goes on, the spatial heterogeneity of the dislocation density increases). Nevertheless, the simple dislocation storage model without recovery explains well enough both the experimental observations of the athermal stage II observed in single crystals deforming by multiple slip at low flow stresses and temperatures (insignificant activation of dynamic recovery processes) and the athermal low-temperature asymptotic Stage II of polycrystals.

\subsection{Dynamic Recovery}

Thermomechanically activatable recovery processes are inherent to plastic strain by dislocation glide. The constant SHR given by Equation (5) is an idealization; together with the process of athermal dislocation density storage given by Equation (3), dynamic processes of dislocation density annihilation are active. Due to the composition of the two effects, the SRH steadily decreases as strain goes on: it is the deformation Stage III mentioned in the introduction. 
Empirically, the SHR evolution, which is strongly dependent on temperature and weakly dependent on strain rate, is very well described by the equation:

$$
\frac{\bar{\theta}}{\bar{\theta}_{0}}=1-\frac{\bar{\sigma}-\bar{\sigma}_{0}}{\bar{\sigma}_{s}^{I I I}(T, \dot{\bar{\epsilon}})-\bar{\sigma}_{0}}
$$

As strain increases, the SHR decreases linearly with the flow stress from an upper athermal limit value $\bar{\theta}_{0}$ to zero. The flow stress grows monotonically and asymptotically tends to a saturation flow stress $\bar{\sigma}_{s}^{I I I}=\bar{\sigma}_{s}^{I I I}(T, \dot{\bar{\epsilon}})$. The integration of Equation (6) leads to the Voce stress-strain shown in Equation (1).

In terms of the underlying evolution of the dislocation density and on account of Equation (4), Equation (6) corresponds to the Kocks-Mecking equation of evolution of dislocation density in Stage III [3]:

$$
d \rho /(d \bar{\varepsilon})=M\left(\beta \frac{\sqrt{ } \rho}{b}-\eta \rho\right)
$$

where the parameter $\eta=\eta(T, \dot{\bar{\varepsilon}})$ depends on the temperature and strain rate in parallel with the behavior of the saturation flow stress. Kocks and Mecking [3] have discussed in detail such dependence: the process of dynamic recovery occurs via the interaction of mobile dislocations with specific sites of the stored dislocation structure under the action of the local flow stress (the effective stress, superposition of the macroscopic flow stress, and the local internal stress) and thermal activation. The activation energy, constant all along Stage III, shows a logarithmic dependence on effective stress.

The recovery processes intervening in Stage III are most probably more than one. One of them is a partial collapse of stored Orowan loops (remnants of gliding dislocations encircling regions of dislocation density higher than the mean) under the forward stress of gliding dislocations of the same sign; another obvious one is the annihilation of segments of the gliding dislocations with segments of opposite sign from the stored or mobile dislocation density.

Surely cross-slip plays a decisive role in those dynamic recovery processes, hence the observed influence of SFE. A close examination of the two terms of Equation (7) supports this idea: when a dislocation sweeps a surface $S$ when gliding across a crystal volume, the number of storage sites per unit surface determine a stored length per unit volume scaling with the current density of dislocations, i.e., Equation (3). Simultaneously, the gliding dislocation explores a volume of $S \cdot h(T, \dot{\bar{\epsilon}})$ above and below the swept surface, where several activatable recovery sites per unit volume reside, each one determining the annihilation of a dislocation length. On account of Equations (2) and (7), the dislocation length eliminated per unit volume should be

$$
\Delta \rho^{-}=-\eta b \rho \sqrt{\rho}
$$

which is dimensionally compatible with the product of the explored volume times a number of activatable sites per unit volume related with the dislocation structure, i.e., scaling as $N \sim \rho^{3 / 2}$, times a fixed annihilated length per site, i.e., a length independent of the scale of the structure.

The Kocks-Mecking model for Stage III is astonishingly simple, effective, and convincing, hence its widespread use in simulations of crystalline plasticity using dislocation densities as internal variables [4].

For a given material, all stress-strain curves collapse in a straight line linking two points, $\bar{\theta} / \bar{\theta}_{0}=1$ on the ordinate with $\left(\bar{\sigma}-\bar{\sigma}_{0}\right) /\left[\bar{\sigma}_{s}^{I I I}(T, \dot{\bar{\epsilon}})-\bar{\sigma}_{0}\right]=1$ on the abscissa in a normalized SHR versus flow stress diagram, as shown in Figure 2. Of the two parameters defining Stage III, the quasi-universal value of the first one $[2,3]$ is:

$$
\bar{\theta}_{0} / G^{*} \cong 0.05 \text {. }
$$


The temperature and strain rate dependence of the second term, $\left[\bar{\sigma}_{s}^{I I I}(T, \dot{\bar{\epsilon}})-\bar{\sigma}_{0}\right]$, needs to be characterized for each material, although its functional form has been given by Kocks and Mecking [3].
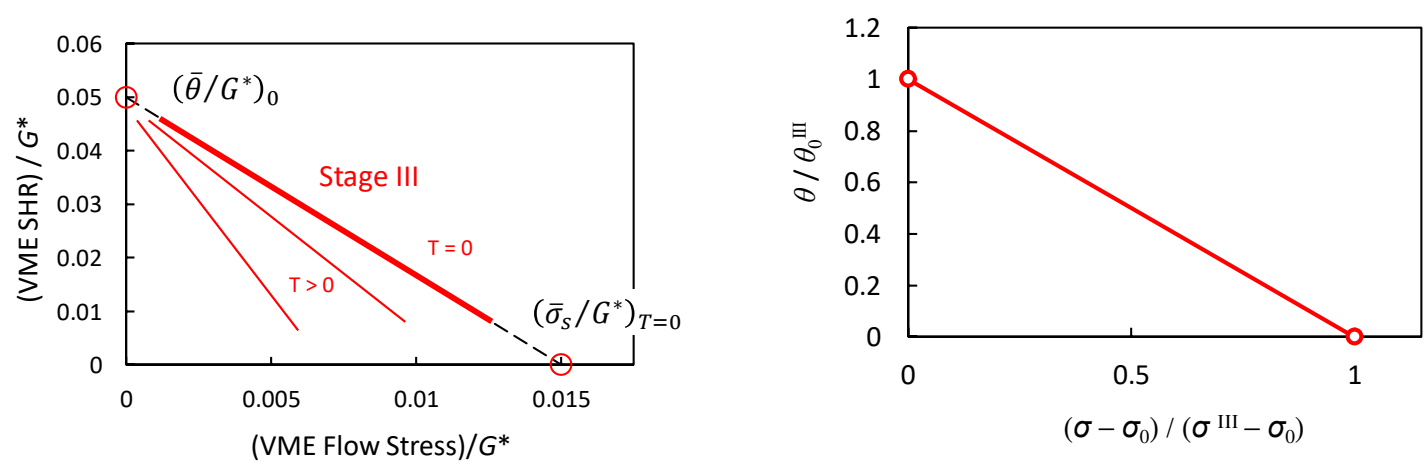

Figure 2. Sketch of Stage III of plastic deformation according to the model of Kocks and Mecking [3].

It is interesting to know, at least approximately, the upper (athermal) limit of the flow stress, governed by the athermal saturation value of Stage III dislocation density. For pure $\mathrm{Cu}$, such a limit flow stress value is:

$$
\left[\left(\bar{\sigma}_{s}^{I I I}\right)_{0}-\bar{\sigma}_{0}\right] / G^{*} \cong 0.015
$$

It corresponds to a dislocation density of the order of

$$
\left(\rho_{S}^{I I I}\right)_{0} \cong 10^{16} \cdot \mathrm{m}^{-2}
$$

These two limit values are probably valid for other crystals too, at least as order of magnitude figures, particularly for body-centered cubic (bcc) metals deformed at temperatures above their low-temperature threshold (more in general, when their flow stress is not dominated by the lattice friction stress) and for hexagonal close-packed (hcp) metals.

Fifty years ago, those limits were thought to be the intrinsic limits of strain-induced strengthening of single-phase crystalline materials, at least in many academic backgrounds.

\section{3. "Large" Strains $(1 \widetilde{<} \bar{\epsilon} \widetilde{<} 10)$}

Interest in exploring and understanding the microstructural basis of the mechanical effects of large strains in crystalline materials arose in the 1960s. Useful strains in tension and compression tests that were most often used earlier for studying plastic behavior were limited by gross deviations from the near-uniform strain and strain rate: the development of localized deformation (necking in tension) or barreling (from friction) in compression.

Scientific interest in large strains was preceded by the technical need of reliable knowledge of stress-strain behavior for improving large-strain processes such as cold rolling, wire drawing, forging, or sheet-forming (reliable input for numerical simulations and knowledge of the structural state of the product). Torsion tests (no external geometry changes in the deforming specimen) or intermittent tension tests during the incremental accumulation of strain by well-designed rolling or wire drawing passes (quasi-free of strain heterogeneities and redundancies [10]) were already extensively used for such purpose since the 1950s (see [9] for a review). As a result, the domain of large plastic strains became available for study, at least for relatively ductile materials.

It soon became evident that no saturation occurs after Stage III, but that a new deformation stage appears at large plastic strains, "Stage IV", which maintains a weak and decreasing SHR well inside the large strain range, $1 \widetilde{<\varepsilon} \widetilde{\varepsilon} 10[2,3,9,11,12]$. Stage IV was inaccessible to studies based on tensile tests because the stage III-IV transition occurs for $\bar{\theta} \cong 0.3 \bar{\sigma}$ [13], i.e., for strains larger than the tensile strain determining the onset of mechanical instability in tension, which is given by the Considère criterion, $\bar{\theta}=\bar{\sigma}$. 
Figure 3 shows a good set of stress-strain curves of commercial purity copper measured in torsion inside the temperature and strain rate range considered in this paper. The characteristics of the stages III-IV are conspicuous. By using the same scaling employed for Stage III (Figure 2), the stress-strain curves of three fcc metals of varying SFE, measured at different temperatures, collapse rather well in a single master curve encompassing both Stages III and IV (Figure 4). This means that although the athermal mechanisms of dislocation storage in Stage IV differ from those of Stage III (they are much weaker), the temperature dependence of Stage IV is nearly the same as that in Stage III.

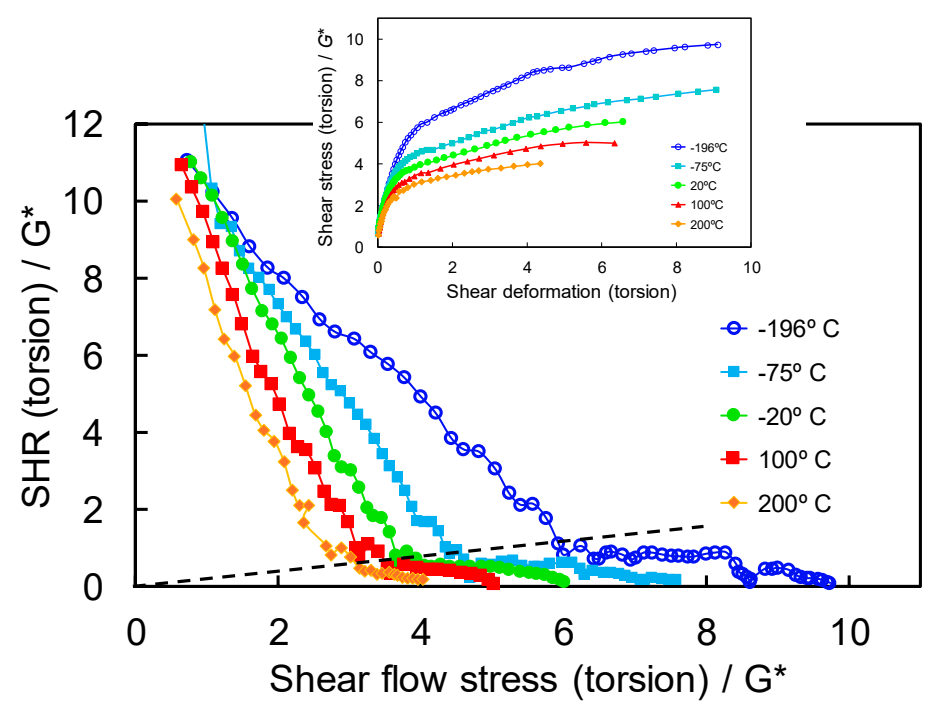

Figure 3. Shear strain-hardening rate vs. shear flow stress in torsion of $99.98 \% \mathrm{Cu}(77,198,293,373$, and $473 \mathrm{~K}$ ) deformed at a Von Mises equivalent (VME) strain rate $\dot{\bar{\varepsilon}}=8 \times 10^{-3} \mathrm{~s}^{-1}$. The inset shows the shear strain vs. shear flow stress curves. Replotted from Alberdi [11].

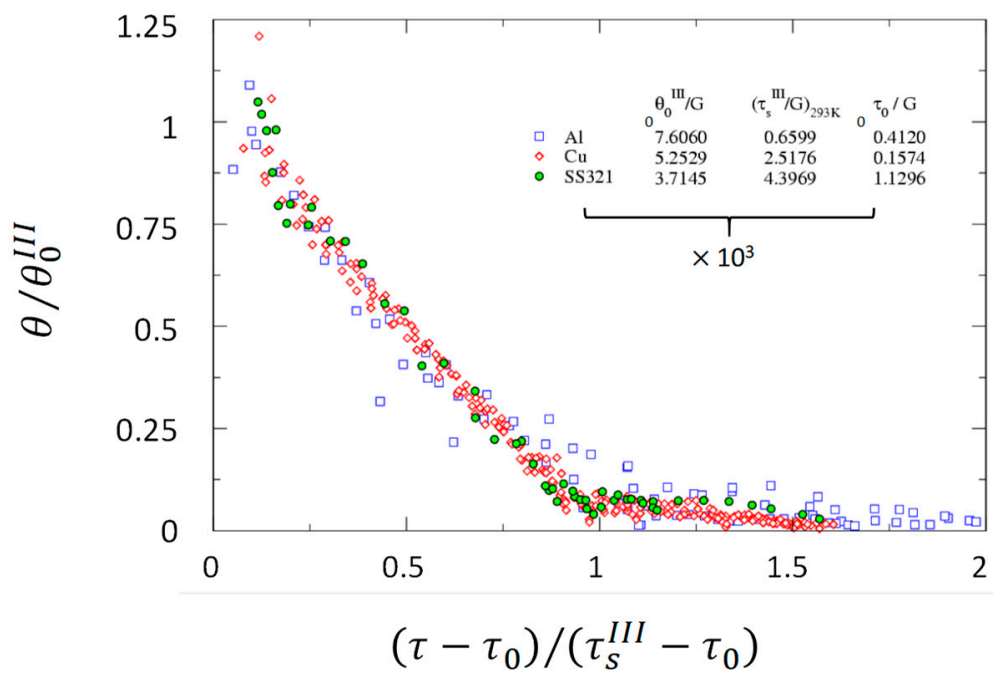

Figure 4. Torsional work-hardening rate vs. flow stress data of $99.98 \% \mathrm{Cu}(77,198,293,373$, and $473 \mathrm{~K})$, $1050 \mathrm{Al}(77,198,293$, and $373 \mathrm{~K})$, both deformed at $\dot{\bar{\varepsilon}}=8 \times 10^{-3} \mathrm{~s}^{-1}$ and austenitic SS321 stainless steel $\left(20^{\circ} \mathrm{C}\right.$ and $\left.200{ }^{\circ} \mathrm{C}\right)$ deformed at $\dot{\bar{\varepsilon}}=2.3 \times 10^{-3} \mathrm{~s}^{-1}$. The numerical data inserted in the figure correspond to crystallographic slip strain vs. CRSS (critical resolved shear stress) behavior; a Taylor orientation factor $M=3$ should be employed to transform them into VME values (i.e., factors $M$ and $M^{2}$ for respectively the flow stress and the SHR). Replotted results from Alberdi [11]. 
For copper or aluminum, as shown in Figure 5, the asymptotic athermal limit at the apparent end of Stage IV is:

$$
\left[\left(\bar{\sigma}_{s}^{I V}\right)_{0}-\bar{\sigma}_{0}\right] / G^{*} \cong 0.024 \text {. }
$$

It approximately corresponds to a dislocation density:

$$
\left(\rho_{s}^{I V}\right)_{0} \cong 2.6 \times 10^{16} \mathrm{~m}^{-2}
$$

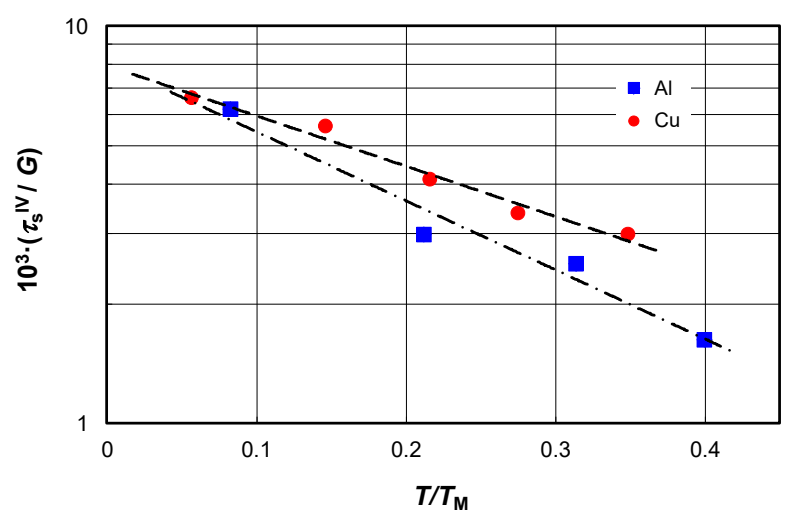

Figure 5. Normalized crystallographic slip shear flow stress (from torsion tests, VME strain rate $\dot{\bar{\varepsilon}}=8$ $\times 10^{-3} \mathrm{~s}^{-1}$ ) at the (apparent) saturation of Stage IV of commercial purity copper and aluminum as a function of homologous test temperature. The athermal limit is about $0.008 G^{*}$. Using an orientation factor $M=3$, the VME athermal saturation flow stress for these two face-centered cubic (fcc) metals would be $0.024 G^{*}$. Data from Alberdi [11].

Either structural damage (precursor of ductile failure) or the emergence of another stage endowed with a powerful dynamic recovery mechanism that soon annihilates the SHR (a possible Stage $\mathrm{V}$, [12]) precludes experimentally approaching those limits in the realm of "large strains". However, a retardation of the apparent reaching of the saturation flow stress by performing the plastic deformation under a hydrostatic pressure (at the basis of the "severe plastic deformation" processes to be described in the next two sections of this paper) was experimentally observed. Thus, it seems that "Stage V" might be a spurious plastic deformation stage, at least for single-phase metallic alloys (however, an unrelated Stage V has been observed in diamond-cubic semiconductors Ge and Si deformed at high temperature, $\left.T \geq 0.65 T_{\mathrm{M}}[14]\right)$.

The explanation of Stage IV is far from complete. The strain-induced processes of dislocation storage and recovery do not maintain the geometrical similitude-based storage law conducive to Equation (3) or the dynamic annihilation law, as shown in Equation (8). Consequently, a progressive deviation from the Voce stress-strain law as Stage III goes on is expected. Furthermore, the existence of processes additional to the main process responsible for Stage III but weakly contributing to hardening is very plausible; their effect would be only detectable when dynamic recovery has nearly neutralized the main hardening contribution to Stage III. Two of them are as follows.

- Continuous accumulation of debris (e.g., dipolar debris) ancillary to the main process of statistical storage and the dynamic recovery of dislocations (the interaction of mobile dislocations with the current total dislocation density present and with other defects of any dimension) [13],

- Accumulation of a slowly increasing density $\rho_{g}$ of geometrically necessary dislocations (GND) coupled to the mesoscopic plastic strain gradients inherent to the heterogeneity of the evolving structure $[15,16]$.

However, other authors explain the evolution of hardening along the III-IV-V stages without resorting to any micromechanistic transition affecting the storage or annihilation of dislocation density, 
i.e., as the deviation from the ideal Stage III mentioned earlier. For instance, Estrin et al. assume that the apparent transition defining the stages is merely the result of a "concerted action" of the deformation of cell interiors and cell walls considered as two phases of a composite, each with their own hardening and softening mechanisms, under the condition of a continuous independent shrinking of the cell size and of the thickness of the cell walls [17]. It may be that Stage IV stems from a combination of factors. The similarity of the thermal activation of the recovery processes working in Stages III and IV deserves further analysis, particularly for explaining the recovery of $\rho_{g}$ at a microscopic level, as GND density is linked to the presence of (very real) mesoscopic strain gradients. Either the strain gradients tend to disappear as deformation goes on or the GNDs within dislocation cells walls disappear by the transformation of subgrains in grains whose highly misoriented boundaries are not anymore built with lattice dislocations but with GBD, grain boundary dislocations; perhaps, what we observe is a superposition of both phenomena.

\section{The Case of Large Strains by Axisymmetric Elongation of BCC and HCP Polycrystals}

Stage IV and the limits of strength and dislocation density expressed by Equations (12) and (13) are not the whole story of stress-strain behavior at large strains: the behavior is strain-path dependent. For instance, axisymmetrically elongated (by wire drawing) bcc and hcp metals display a constant SHR beyond the usual Stage III, which is concomitant with the development of a unique structure of elongated cells, subgrains, and grains with ribbon-shaped cross-sections that require a characteristic curling for maintaining the compatibility of the polycrystalline aggregate "Van Gogh sky" structure $[18,19])$. Such curling amounts to the axial bending of these ribbons that, combined with their structural refining, amounts to a continuous increase of the mesoscopic gradients, i.e., a continuous increase of GND density contributing to sustaining the SHR up to the largest technologically possible deformations accessible to wire drawing $(\bar{\varepsilon} \approx 10)$. Such peculiar behavior is due to the development of a crystallographic texture that promotes the deformation of the crystal units by plane-strain elongation, despite the axially symmetric deformation imposed to the wires. The same metals (e.g., iron [20]) behave differently when deformed through other strain paths. The phenomenon of a combined continuous injection of GND density and enhanced structural refining makes it possible to reach and often surpass the above-stated Stage III athermal limits of flow stress and dislocation density in wire-drawn bcc and hcp metals of high melting point.

The extension of the constant SHR stage of bcc and hcp metals beyond its current wire drawing limit is an interesting question that is not exempt of practical implications, because the sustained SHR would allow for reaching flow stresses and dislocation densities in fine wires well beyond the maximum values available today $[21,22]$.

\section{SPD, “Severe Plastic Deformations" $(\bar{\epsilon} \widetilde{>} 10)$}

\subsection{ECAP}

Largely strained bulk specimens are both desirable for the macroscopic testing of properties and attractive for many possible technical applications. The accumulation of a big number of passes leading to $\bar{\epsilon} \widetilde{<} 10$ by wire drawing or rolling only furnish thin filaments or foils less than $100 \mu \mathrm{m}$ thick; technological constrains preclude the processing of thicker sections of very hard materials. Moreover, often the processing is limited by ductile or brittle fracture nucleated from strain-induced structural damage, because deformation in rolling or wire drawing is imparted under hydrostatic pressure levels below the current VME flow stress value. Similarly, although the torsion of cylindrical bulk specimens does not introduce important shape or size changes of the test specimens, the hydrostatic pressure in free torsion is zero; VME strains of 5 are rarely reached before fracture in free torsion.

Before the 1980s, Segal and co-workers developed in the Soviet Union a process allowing for, ideally, indefinite accumulation of extrusion passes imparting about 1 VME strain per pass to bulk bar-shaped specimens under high pressure without significantly changing their external shape. 
The process, which was dubbed ECAE or ECAP, acronyms of equal-channel angular extrusion or pressing, is extrusion through a channel of uniform section with a sharp kink of about $90^{\circ}$ [23,24]. When the material goes through the kink of the channel, it endures a simple shear under a hydrostatic compression of the order of the flow stress of the material. Deformation per pass is about unity for a $90^{\circ} \mathrm{kink}$, and in practice, the extrusion can be repeated up to near 20 passes, i.e., $\bar{\epsilon} \widetilde{\epsilon} 20$ (most materials become so strong after those strains that fail by ductile or brittle fracture further in the process). The process and its potential for modifying the material structure by "severe plastic deformation", SPD, was soon intensively exploited by Valiev and co-workers $[25,26]$. The possibilities offered by the ECAP process and its variants for exploring the response of materials to very large plastic strains made a big impact, stimulated the invention of other new SPD processes, and triggered the production of a tremendous amount of related bibliography in the last 40 years. Many comprehensive reviews on the subject have been published, e.g., [27-29].

The extension of the stress-strain analysis provided by ECAP does not change the most important conclusions reached from studies in the "large strain" range: Stage IV carries on toward its asymptotic limit without signs of any Stage V. Figure 6 shows results for commercially pure $\mathrm{Cu}, \mathrm{Ni}, \mathrm{Fe}$, and $\mathrm{Ti}$ deformed by ECAP at room temperature (data from refs. [30-46]). Although there is much scatter in the results (inherent to the ECAP process and its analysis: the plastic heterogeneity of the deformed samples, different variants of the strain path used by different authors, testing by tension or by hardness), it seems clear that an apparent saturation of the flow stress occurs near a VME strain of 7 . Averaging the available flow stresses beyond $\bar{\varepsilon}>7$ for each metal, the values compare well with the saturation flow stress of Stage IV, $\left(\bar{\sigma}_{s}^{I V}\right)_{300 K^{\prime}}$ obtained by extrapolation to zero SHR, the results from conventional torsion tests, or from rolling at $300 \mathrm{~K}$, e.g., $[2,3,9,11,12]$ and Figures 4 and 5.

The obvious question now was to go beyond the maximum feasible ECAP strains in order to verify whether the saturation of Stage IV is the true dynamic steady state in low/medium temperature plasticity. Surprisingly, an elegant deformation process was available since the early 1930s to settle this question: HPT, torsion under (very) high pressure.

\section{2. $H P T$}

Percy Bridgman's main research subject was the physical behavior of materials under high hydrostatic pressure (Nobel prize, 1946). Among many other topics, he was interested in the high-pressure effects on plastic deformation and fracture ([47] is the synthesis of his work on this subject). He developed many devices for high-pressure studies and specially the "Bridgman anvils", where a coin-shaped sample is squeezed in a shallow cavity between two otherwise flat anvils acted by an axial compressive force. The sample diameter matches that of the cavity, and its thickness lightly exceeds the height of the cavity when the two anvils are in contact. Under enough compressive force, material flows plastically and is extruded through the thin spacing between the anvils, which is a situation that creates a hydrostatic stress state in the material that grows exponentially as the spacing decreases, so that hydrostatic pressures of several GPa are easily reached. Applying now a rotation to one of the anvils, you have a torsion test of the disk (dragged by friction) into which in contrast with most other SPD processes, the hydrostatic compression is decoupled from the torque performing the torsion, i.e., it can be controlled by the axial compressive force applied to the anvils independently of the flow stress of the material being tested. 


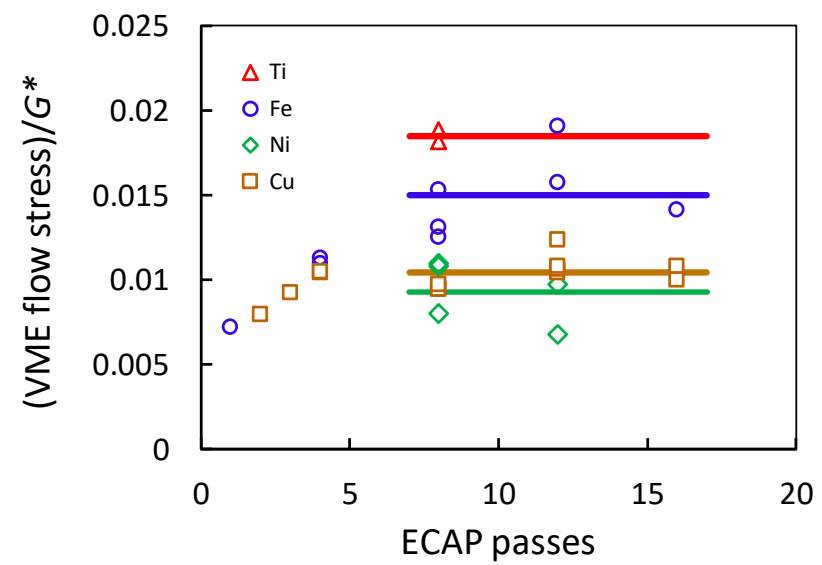

Figure 6. VME flow stress data (ultimate tensile strength, UTS or a third of the Vickers hardness, HV/3) of fcc $99.95 \% \mathrm{Cu}$ [30-35] and 99.98\% Ni [36-39], body-centered cubic (bcc) 99.95\% Fe [40-44] and hcp $99.5 \%$ (grade 1 ) $\mathrm{Ti}[45,46]$ as a function of the number of equal-channel angular pressing (ECAP) passes performed at $300 \mathrm{~K}$ (one pass imparts about one unit of VME strain). Dotted lines are the average of values of flow stress between 8 and 16 passes for each metal; an apparent saturation stress is reached at $300 \mathrm{~K}$ beyond $7 \mathrm{ECAP}$ passes for at least $\mathrm{Cu}, \mathrm{Ni}$, and $\mathrm{Fe}$.

With enough pressure, the structural damage and crack propagation in the sample can in principle be suppressed, and indefinite simple shear strains can be applied. Moreover, recording the torque versus rotation angle offers the possibility of directly deriving the shear stress-strain curve. On the other hand, shear strain increases linearly from zero at the center of the disk to a maximum at its periphery. By measuring the hardness along the radius of a single deformed sample, many discrete points of the stress-strain curve from zero to the maximum deformation at the outer surface of the sample can easily be obtained.

Bridgman studied the HPT behavior of many materials. However, its device and results were practically overlooked by materials scientists (with the noteworthy exception of the rediscovery of the method made by Erbel, which was virtually overlooked for a long time, too [48,49]), until the publications of Valiev and co-workers, who had started using the HPT device in the 1980s [25,50].

A wealth of studies on the stress-strain, structure, and properties of materials severely strained by HPT has since then inundated the bibliography, VME strains larger than 100 being easily attainable even in materials of poor ductility [29,50-55].

Although ideally indefinite shear strain can be applied by HPT, several experimental problems arise after the application of a few rotations to the mobile anvil (mainly, the maintenance of the geometry of the disk without damage starting from its periphery); the consequence is that most HPT studies are restricted to VME strains smaller than 50. In that strain range and for the materials and test conditions considered in this paper, the stress-strain behavior does not qualitatively differ from that seen with the ECAP process (e.g., see in the reviews cited above [29,49,51-55]). However, quantitatively, the saturation stresses estimated from ECAP are only apparent, the very weak SHR of the terminal Stage IV continues its decline much longer than expected, and the saturation stresses estimated from HPT tests are up to $20 \%$ larger (no wonder if one accepts for Stage IV the validity of the Kocks-Mecking model or one of its variants, leading to a Voce-type equation that only asymptotically approaches a steady state).

\section{Ultra-SPD, “Ultra-Severe Plastic Deformations” ( $\bar{\epsilon}>500)$}

Quite recently, Edalati [56] has published the microhardness versus strain results of pure fcc (Ni), bcc $(\mathrm{Fe})$, and HCP (Ti) deformed by HPT well beyond 1000 units of shear strain at room temperature $\left(0.155 \leq T / T_{m} \leq 0.174\right.$ for these metals), which is a realm that he has dubbed "ultra-SPD strains". Edalati and co-workers have found that around $\bar{\epsilon}>500$, the stress-strain curves of the three metals present an 
inflection point giving access to what looks to be a new deformation stage that significantly strengthens the material over the Stage IV saturation flow stress if the strain is continued far enough (Figures 7 and 8). The strengthening is not due to any pressure-induced phase change (the pressure employed for HPT straining $\alpha \mathrm{Ti}, 2 \mathrm{GPa}$, is well below that required for its transformation to $\omega \mathrm{Ti})$. The pattern of behavior is similar for the three metals. The stronger the metal (because of its homologous deformation temperature and SFE), the earlier appears the SHR after the Stage IV saturation plateau.

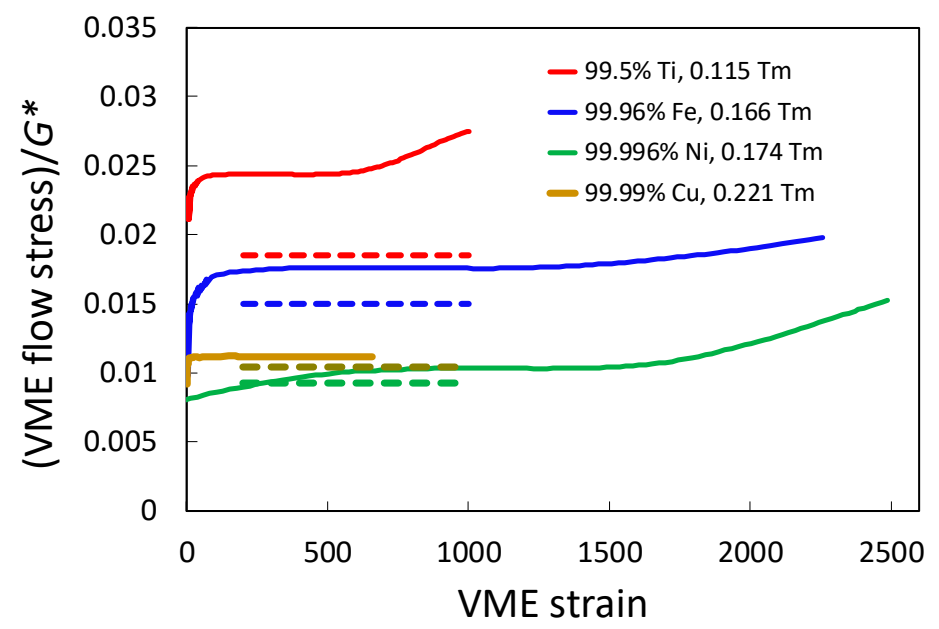

Figure 7. The stress-strain behavior of pure fcc Ni, bcc Fe, and hcp Ti ultra-deformed by torsion under (very) high pressure (HPT) (respectively 2, 6, and $2 \mathrm{GPa}$ applied pressure) at room temperature beyond VME strains of 1000. The VME flow stress has been measured as HV/3, which is one-third of the Vickers microhardness. Replotted from Edalati [56]. The HPT curve of fcc $\mathrm{Cu}$ (6 GPa axial pressure) is from Edalati et al. [57]. Dotted lines are the average Stage IV apparent saturation flow stress of metals of similar composition deformed by ECAP in the range $8 \leq \bar{\varepsilon} \leq 16$ (Figure 6). Homologous deformation temperatures are indicated in the figure. The SFE of the four materials at RT increase in the inverse order of their homologous deformation temperature from approx. $45 \mathrm{~mJ} / \mathrm{m}^{-2}$ of Cu to approx. $180 \mathrm{~mJ} / \mathrm{m}^{-2}$ of Ti.

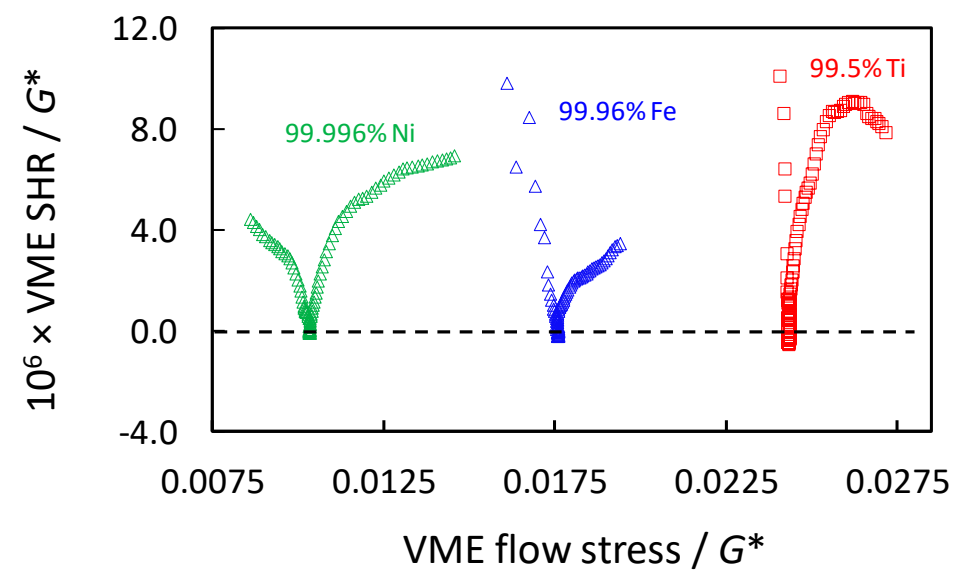

Figure 8. Normalized VME strain hardening rate, $S H R / G^{*}$ vs. normalized VME flow stress, $\bar{\sigma} / G^{*}$ for pure Ni, Fe, and Ti ultra-SPD deformed by HPT at room temperature. Derived from the stress-strain curves measured by Edalati [56], as shown in Figure 7. Saturation of Stage IV and emergence of a new hardening stage.

Confirmation that we are dealing with a genuine deformation stage demands further research. However, let us speculate about possible microstructural sources that could explain the observed behavior. 
We should first point out that the ultra-SPD SHR is awfully weak: less than $10^{-5} \mathrm{G}^{*}$ for Ni, Fe or Ti at 300 K, i.e., two orders of magnitude smaller than the weak SHR observed in Stage I of easy-glide single crystals.

Secondly, as this new stage appears only after the saturation of Stage IV, the origin of it cannot anymore be related with the new statistical storage of gliding dislocation lengths, which were fully annihilated by concurrent Stage III dynamic recovery.

Possible origins of such weak SHR are:

- An artefact of the HPT process: as told before, the simple shear of disks by HPT develops a macroscopic gradient of shear strain. The accommodation of such a gradient requires a continuous storage of a density of redundant GND. The gradient is enormous after $\bar{\epsilon}>500$. The gradient can be avoided by using rings of appropriate geometry (as used by Erbel [48]).

- Hardening from accumulation of an increasing density of point defects or their clusters arising by the interaction of gliding dislocations with other dislocation lines or from the processes of dynamic recovery of dislocation lengths. Such point-like defects, i.e., vacancy clusters, represent weak obstacles for gliding dislocations.

- A sudden transition from a laminar shear plastic flow to a turbulent one at the mesoscopic microstructural level; it would trigger the accumulation of a density of GND until reaching some new steady state.

- A transition from the control of the flow stress by the average dislocation density to its control by the current grain size (refined by fragmentation and by the imposed deformation, counteracted by specific recovery mechanisms). The transition would take place at some critical size of the grains.

The first of these four tentative contributions to ultra-SPD behavior cannot be discarded. After a macroscopic shear strain $\gamma$ at the periphery of the disk, the shear strain gradient in the HPT sample amounts to

$$
\chi=\gamma / R
$$

where $R$ is the sample radius. The accommodation of a plastic gradient by redundant dislocations requires the storage of a GND density of about

$$
\rho_{g}=M_{g} \cdot(\chi / b)
$$

with $M_{g} \geq 1$ is an orientation-dependent factor accounting for resolving a simple shear by a combination of dislocations from different slip systems. In the HPT case,

$$
\left(\rho_{g}\right)_{H P T}=M_{g} \cdot(\chi / b)=M_{g}(\gamma / b R) \cong M_{g}\left(M_{\text {shear }} \bar{\varepsilon} / b R\right)
$$

The orientation factor for macroscopic shear strain is $M_{\text {shear }} \cong 1.5$. We can roughly estimate the VME flow stress for ultra-SPD at room temperature for a material such as Fe (i.e., $\left.\left(\bar{\sigma}_{S}^{I V}\right)_{R T} / G^{*}=0.017\right)$, ignoring any possible dynamic recovery of the GND density as the effect of the addition of the two dislocation densities:

$$
\left(\bar{\sigma}_{u S P D}\right)_{R T} / G^{*}=\sqrt{0.017^{2}+\left[M_{\text {tension }} \alpha b \sqrt{\left(\rho_{g}\right)_{H P T}}\right]^{2}} .
$$

Assuming $M_{g} \cong 1.5$ (the orientation factor for simple shear), $M_{\text {tension }} \cong 3, \alpha \cong 0.3, R=5 \mathrm{~mm}$, and $b=0.25 \times 10^{-9} \mathrm{~m}$, the result is shown in Figure 9 together with the experimental Fe curve from Edalati [56]. The hardening in excess of the Stage IV saturation flow stress is of the right order of magnitude, but the pattern of behavior does not match the experimental one; the gradient contribution to the flow stress follows a continuous power law right from the approach of the flow stress to its saturation value at strains smaller than 100 . 


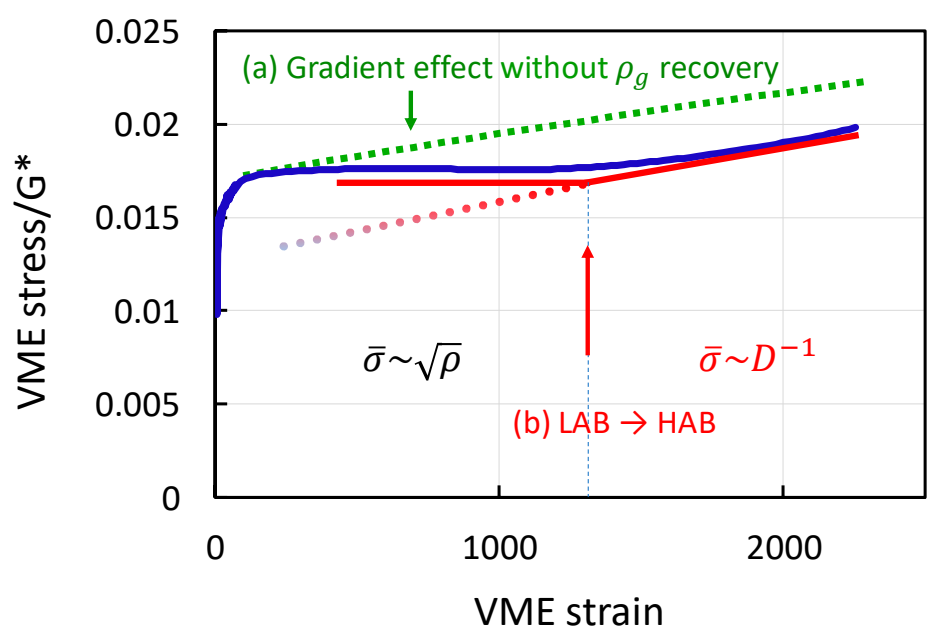

Figure 9. Expected behavior at ultra-severe plastic deformation (SPD) by assuming flow stress control from either (a) saturated statistically stored dislocation density plus geometrically necessary dislocations (GND) density from the HPT shear gradient, Equation (17) or (b) from the 3D dislocation density (cells or subgrains) during Stage IV and from the grain size beyond Stage IV (ultra-SPD range).

The ultra-SPD burst of hardening is only manifest after a long stress plateau indicative of a transition of the process controlling the strain hardening. This points to the third and fourth origins of the ultra-SPD hardening as plausible explanations, because the second one also represents, as the first, a continuous increase of hardening obstacles as far as dislocation interactions occur.

A hypothetical transition from a laminar to a turbulent shear flow needs experimental confirmation; besides microstructural evidences (in the form, perhaps, of shear bands), probably it would be accompanied by a transition of crystallographic texture, too.

Finally, the fourth explanation looks most interesting: one of the main scientific and technical fascinations of SPD processes is their capability of nanostructuring initially single-crystalline or coarse-polycrystalline materials. It is well known since the seminal work of Langford and Cohen [58], which has been many times confirmed thereafter, that the structure of dislocation cells developed in Stage III shrinks in size and develops an increasing misorientation between neighboring cells; the cells progressively sharpen its walls until becoming low-angle boundaries (subgrain walls) and finally, with the progression of Stage IV, the majority of them become high-angle boundaries of new grains of near-nanometric size that SPD continues refining $[9,29,51]$. The grain size evolution shows an exponential decline until an apparent temperature-dependent saturation grain size sets in after shear strains of the order of 50 [59-62]. Such an alleged terminal grain size is in the nanometric range $(\approx 100 \mathrm{~nm})$. Only by ultra-SPD processing has the absence of flow stress saturation been detected; it may be that the grain size is still decreasing at a very slow pace and becomes only conspicuous when the colossal ultra-SPD strain range is explored. Quantitative microstructural studies are needed in order to confirm a decrease of grain size concomitant with the ultra-SPD hardening stage. Anyway, if we assume that it is the case, we can advance an explanation.

The classical static Hall-Petch relationship $\left(\bar{\sigma} \sim D^{-1 / 2}\right)$, which is mainly justifiable by the strengthening from a grain-size-dependent intragranular dislocation density level, deviates toward a $\bar{\sigma} \sim D^{-1}$ relationship upon further grain size refining. Something akin to it could be at the base of the ultra-SPD transition.

As the strain progresses in Stage IV, most microstructural boundaries have converted into true grain boundaries (misorientation larger than $\approx 12^{\circ}$ ), and grain size has become sub-micrometric. The flow stress is controlled by the stress for long-range dislocation glide through the intragranular dislocation forest, as shown in Equation (4), which is equivalent to a critical dislocation line curvature. If the grain size is big enough relative to the effective inter-dislocation distance, the mobile dislocation line ends by reaching the grain boundary where it is either integrated as an extrinsic defect there 
or totally or partially penetrates the neighboring grains. The maximum curvature required for the intragranular travel of mobile dislocation lines is imposed by the Stage IV dislocation density at saturation. If the grain size was being continuously refined upon straining through a monotonic strain path, a critical grain size would be reached for which the fitting of the curvature of its cross-section would be more flow stress demanding for the dislocation than its gliding through the intragranular dislocation density. From that point on, the flow stress would be controlled by the dynamically evolving grain size through an approximate $\bar{\sigma} \sim D^{-1}$ relationship [22,63,64]. This possible behavior is sketched in Figure 9, too.

Once the Stage IV saturation is approached, the grain fragmentation processes related with new net dislocation storage are not anymore operative. The further evolution of grain size merely comes from its size and shape change resulting from the strain path-dependent mesoscopic strain (very effective in a wire drawing of bcc or hcp metals but very inefficient in the simple shear deformation), which is counteracted by processes of dynamic annihilation of the GB surface. For instance, the process of shear-coupled boundary migration, SCBM, both significantly contributes to the plastic deformation and to the GB surface annihilation at low temperature when grain size is in the nanometric range, particularly in macroscopic shear [59]. It happens likewise with grain boundary sliding, GBS, which is particularly favored in simple shear because of the progressive orientation of the GB toward the macroscopic shear plane (contributes to strain and weakens the shape change relative to the macroscopic one), but very ineffective in wire drawing, which orients the microstructure in the axial direction. For our explanation to be valid, these dynamic GB recovery processes should not be able to completely suppress grain refining coming from the effect of the macroscopic strain.

Figure 10 compares the stress-strain evolution of "pure" iron and "pure" titanium either deformed by wire drawing $[58,65]$ or by HPT $[56,60,66]$. The trend of curves qualitatively agrees with the above given description $[22,58,63,64,67]$. In large-strain simple shear (HPT) of bcc iron, the minimum average dimension of deforming grains would evolve, in the absence of dynamic recovery processes, as

$$
\frac{D}{D_{c}} \cong \frac{1}{\sqrt{3}\left(\epsilon-\epsilon_{c}\right)} .
$$

In wire drawing, instead,

$$
e^{-\left(\varepsilon-\varepsilon_{c}\right) / 2} \geq \frac{D}{D_{c}} \geq e^{-\left(\varepsilon-\varepsilon_{c}\right)} .
$$

The suffix $c$ indicates the transition of control of the flow stress by glide of the mobile dislocations through the dislocation forest to dislocation bowing-controlled glide. In fact, both Equations (15) and (16) must incorporate a lag factor that is much smaller than 1 for shear and about 1 for axisymmetric drawing, on account of the GB-related processes contributing to strain and dynamic recovery. It is easy to see that the shear lag factor must be very small in order to match the SHR observed in ultra-SPD $\left(\bar{\theta}_{u S P D}<10^{-5} G^{*}\right)$. It is interesting to remark that Hosokawa et al. [68] who, as noted by Edalati [56], first observed SHR after a large plateau of the HPT stress-strain curve of $\mathrm{Fe}$, also related such SHR revival with the hardening of iron by large-strain wire drawing and its relationship with the grain size evolution enforced by the macroscopic shape change. 


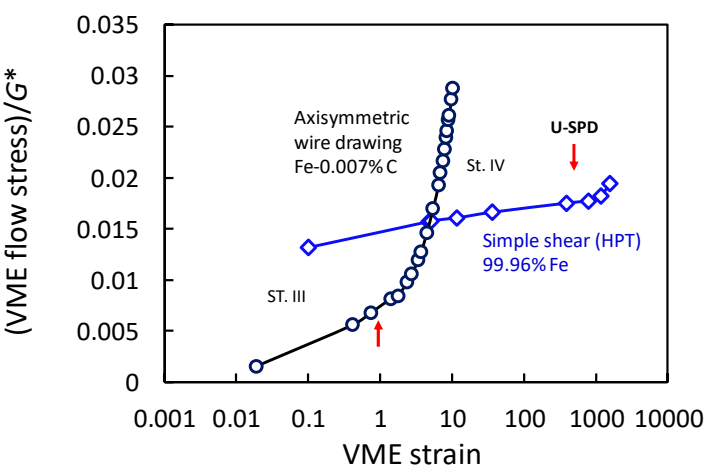

(a)

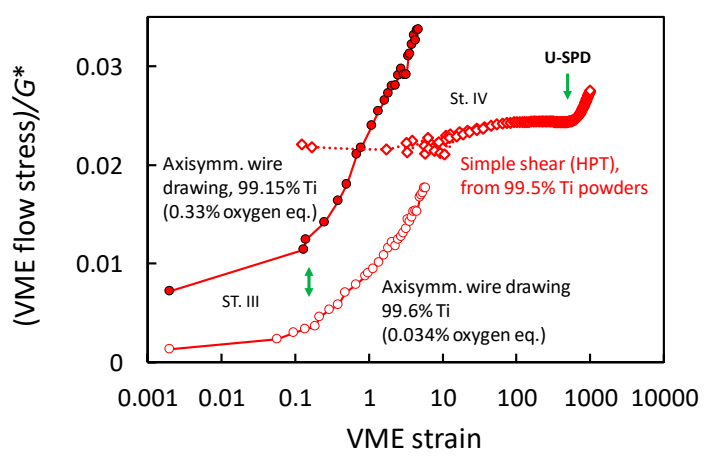

(b)

Figure 10. Stress-strain of (a) Fe and (b) Ti deformed by axisymmetric drawing (Fe- $0.007 \% \mathrm{C}$, Langford and Cohen [58], 99.15\% and 99.6\% Ti, Biswas [65], UTS from tensile tests) and by simple shear (HPT, 99.96\% Fe and 99.5\% Ti, Edalati [56,66], HV/3). Notice the logarithmic scale of the abscissa. The difference in the flow stresses at small/moderate strains may be due to differences in the friction-like flow stress fraction (chemical composition, interstitial content in particular) and initial grain size of the materials, the different testing method for flow stress determination, and the unaccounted compressive deformation of the HPT disk at the beginning of the HPT shear test.

The case of fcc nickel is remarkable. No conclusive information can be obtained from available wire drawing stress-strain curves (a maximum VME strain of about 2 [69]). However, two independent flow stress versus rolling strain curves (plane strain elongation) do show an awakening of strain hardening after a Stage IV plateau reminiscent of the transition observed in HPT deformation at very much larger strains [70,71]. Figure 11 displays one of these rolling deformation stress-strain results together with a wire-drawing curve and the HPT results previously shown. The similarity with the behavior exhibited by iron or titanium (Figure 10) is evident. In rolling, in the absence of dynamic recovery, the evolution of the minimum average dimension of deforming grains would be:

$$
\frac{D}{D_{c}}=e^{-\left(\varepsilon-\varepsilon_{c}\right)}
$$

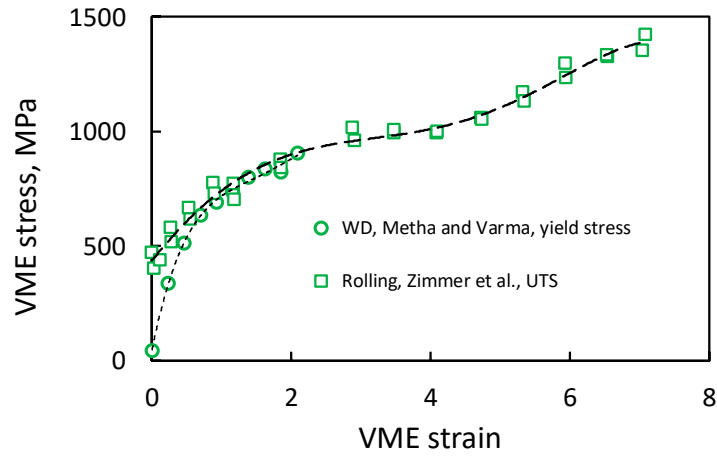

(a)

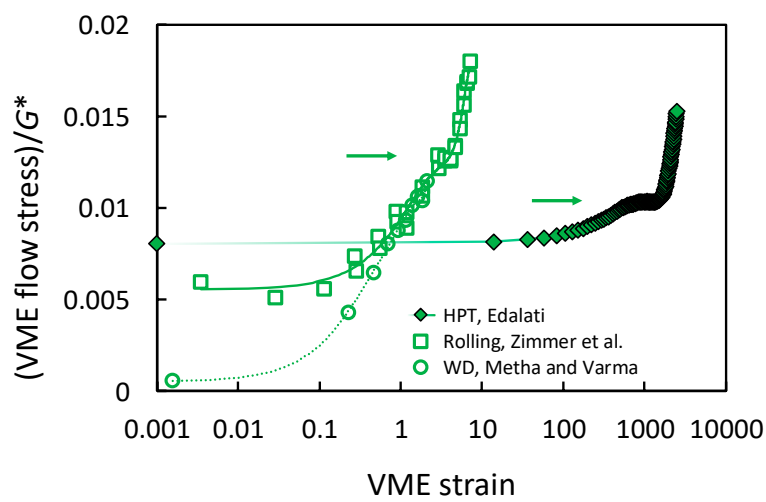

(b)

Figure 11. Stress-strain of commercial purity nickel (Ni 200, 99.4\% Ni) deformed by (a) wire drawing (replotted from [69] and rolling (replotted from) [71]) compared with (b) the behavior of 99.996\% Ni deformed by HPT (ultra-severe SPD) (replotted from [56]). In figure (b) arrows point to the seeming ultra-SPD transition. 
According to our tentative explanation, the critical grain size for the ultra-SPD transition would be obtained from equating the critical bowing stress in the grain [22] with the saturation flow stress due to the terminal dislocation density of Stage IV given by Equation (12):

$$
\frac{M \tau_{c}}{G^{*}}=\frac{\varphi M}{2 \pi(1-v)} \frac{b}{D_{c}}\left(\ln \frac{D_{c}}{\varphi b}+0.7\right)=0.024 .
$$

A shape-factor $\varphi \widetilde{>} 1$ relating the required local critical bowing dislocation diameter with the average grain size has been introduced in Equation (21). With a Poisson ratio of $v=0.3, b=0.25 \mathrm{~nm}$, and $M=3$, the predicted average critical grain size would be $D_{c}=40 \varphi \mathrm{nm}$.

\section{Beyond Current Ultra-SPD?}

One may now wonder what would happen with the strength and structure of materials if strains by wire drawing or by HPT were continued still much further, to 100,000 or more in the latter case (Edalati [56] has imparted HPT shear strains up to $10^{5}$ to several materials). Difficulties for guaranteeing experimental results free from artifacts after such enormous strain levels surely are considerable. However, theoretical and numerical simulations can shed some light on this question [21,22,72]:

(a) About the strengthening by statistically stored dislocations in the absence of macroscopic (externally imposed) plastic strain gradients, we have the athermal limits of dislocation density and flow stress given by Equations (12) and (13). Those values are extrapolations of experimental results. Experimental values of dislocation densities obtained after plastic deformation in conditions close to athermal are in the same range: $10^{16} \mathrm{~m}^{-2}$ after shock experiments or $10^{17} \mathrm{~m}^{-2}$ after deformation at $4.2 \mathrm{~K}$. Similarly, atomistic simulations of shock deformation of pure $\mathrm{Cu}$ or Ni show peak non-equilibrium dislocation densities up to $10^{18} \mathrm{~m}^{-2}$ that decrease to $10^{16} \mathrm{~m}^{-2}$ after relaxation (for references, see [21]). Thus, the figures given by Equations (12) and (13) are reasonably confirmed.

(b) Non-redundant geometrically necessary dislocation density is immune to most of the recovery mechanisms to which statistically stored dislocation density is vulnerable (mechanisms involving the annihilation of dislocation segments of opposite sign). However, the GND density can also be absorbed and digested in high-angle grain boundaries to the price of a change in their defect structure and associated intergranular misorientation. Disregarding such possible recovery, an absolute "natural" limit to dislocation density of any kind, redundant or not, is inherent to the discrete, atomistic constitution of the crystals. Surprisingly, a variety of different criteria for establishing such limits (geometric, mechanical, thermodynamic) yield a very narrow interval for its value [21]:

$$
0.2 \leq \rho_{\max } \cdot b^{2} \leq 0.3
$$

i.e., about $4 \times 10^{18} \mathrm{~m}^{-2}$ for the metals considered in this paper. From Equation (3) with the $\alpha$ value adequate to the high figure of the dislocation density, the maximum athermal flow stress associated to such dislocation density would be

$$
\left[\left(\bar{\sigma}-\bar{\sigma}_{0}\right)_{\max } / G^{*}\right]_{T=0} \cong 0.3 \text {. }
$$

However, remember that as explained above, such a limit cannot be reached by the plastic deformation of single-phase crystalline materials developing Stage IV because of the emergence of a nanograin structure after large strains and its control of the flow stress (Figure 9).

What should we expect to happen in an alloy where the saturation of Stage IV does not occur? The obvious answer is amorphization. It does not seem casual that the absolute limit value given above for the flow stress coincides with the ideal strength for the irreversible deformation of metallic glasses [21]. 
(c) However, increasing the dislocation density does not seem to be the actual microstructural path for amorphization by deformation. Amorphization by deformation is experimentally observed in many alloys with a high glass-forming ability as a transition from a nanograined to a disordered glassy structure.

Increasing the strains by ultra-SPD HPT or by wire drawing, etc., beyond their current top highs (Figures 7 and 10) is certainly leading to a strength limit, but which one?

Many materials seem to reach a steady state too before amorphization-for instance, pure metals or its dilute alloys. For instance, iron powders deformed by high-energy ball milling at room temperature (high strain rate, non-monotonic strain path) saturate at about $3.5 \mathrm{GPa}\left(0.05 \mathrm{G}^{*}\right)$, well above the apparent saturation value for Stage IV. Its structure is constituted of equiaxed nanograins.

The structure of iron wires drawn to $\bar{\varepsilon}=10$ after the accumulation of a big number of passes is constituted of axisymmetrically oriented elongated nanograins of an equiaxed section randomly rotated about the $\langle 110\rangle$ crystallographic direction. If such a structure were geometrically perfect (ideal crystallographic domains of infinite axial length and separated by perfect, flat intergranular axially oriented walls), it would be unable to develop elongation-coupled grain boundary migration or grain rotation, i.e., it would be resistant to dynamic recovery in the ultra-SPD stage; continued elongation would lead to further strengthening until reaching some critical structural refinement for attaining the disordered state. However, the real structure is far from ideal, and given its extraordinarily fine grain size, it offers opportunity for recovery mechanisms to significantly contribute to arrive at a steady state of a limited GB surface per unit volume. Numerical MD simulations intended to emulate the observed imperfect fibrous structure of drawn Fe wires up to grain sizes in their cross-section as fine as $3 \mathrm{~nm}$ (Figure 12) suggest that the VME flow stress of pure iron wires would saturate at about $5 \mathrm{GPa}$ $\left(0.08 G^{*}\right)$ [22]. This is an estimation of the athermal VME flow stress limit of iron following this unique strain path (the MD result is $6.75 \mathrm{GPa}$ for the saturation stress, of which $1.75 \mathrm{GPa}$ corresponds to a dynamic friction stress because of the very high strain rate employed in the MD simulations $\left(10^{8} \mathrm{~s}^{-1}\right)$, as stated in the caption of Figure 12).

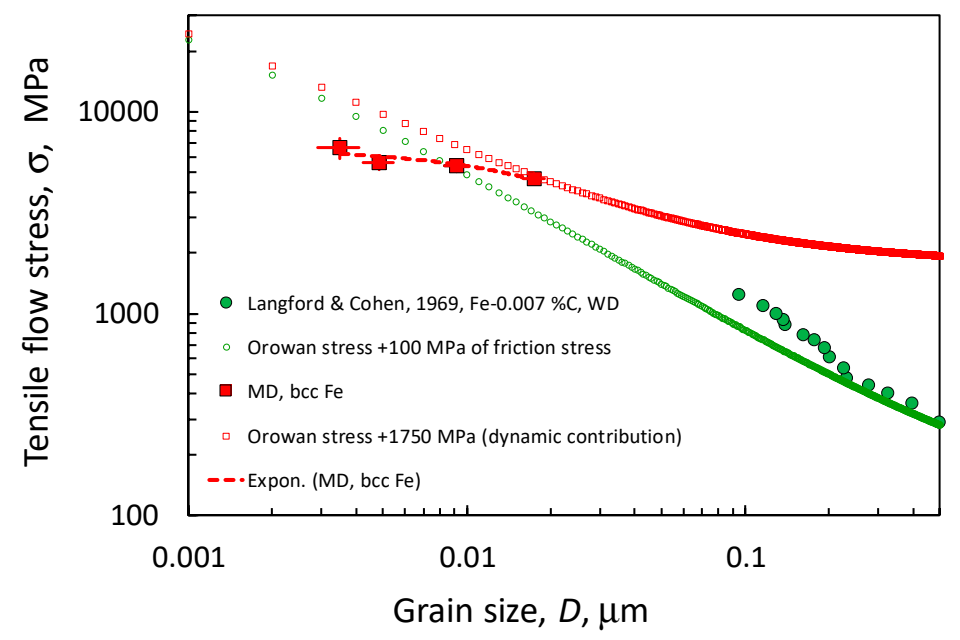

Figure 12. Experimental VME flow stress vs. grain size in the cross-section of $<110>$ textured axisymmetrically drawn iron wires (Fe-0.007\%C, from Langford and Cohen [58]) and MD results (molecular dynamics simulations) of similar (but finer) structures of pure iron from ref. [22]. Superposed: the critical stress for bowing a dislocation to the curvature of the grains (the Orowan equation) plus a $100 \mathrm{MPa}$ additive term representing the friction stress from the lattice (appropriate for $\mathrm{Fe}-0.007 \% \mathrm{C}$ ) or a 1.75 GPa dynamic friction stress (appropriate for the MD simulations because of the very high strain rate employed in the calculations, $10^{8} \mathrm{~m}^{-1}$ [22]). 


\section{Conclusions}

- $\quad$ SPD processes have extended the experimental study of deformation of materials to levels of VME strains unimaginable half a century ago: from 1 to $10^{5} \mathrm{VME}$ strain.

- The effect of plastic deformation on the flow stress and internal structure of materials is path-dependent. One must be aware that both ECAP and HPT, the most performant SPD processes for attaining very large strains in bulk samples, impart simple shear deformation (similar to conventional torsion tests). It is convenient to compare the ECAP or HPT results with results from other more traditional processes imparting large strains, such as rolling (plane-strain elongation, equivalent to pure shear) and wire drawing (axisymmetrical elongation).

- For bcc or hcp materials, wire drawing is much more effective at strengthening or structural refining than SPD processes, because of the unique internal mesoscopic strain pattern associated to a texture that strongly favors internal plane strain elongation, requiring grain interfolding. Ultra-SPD strained Fe or Ti by HPT to a VME of 4000 do not achieve the strength levels obtained by drawing to a VME strain of 10 .

- The results of SPD processes applied to metals refute the existence of a true deformation Stage V, prematurely putting an end to the slow progression of Stage IV toward its alleged steady state. Under the high hydrostatic pressures of SPD processes, such progression continues its path much further than expected from the behavior observed in conventional tension or torsion tests.

- Recently published results of ultra-SPD stress-strain behavior of several pure metals show that a hardening transition occurs after a very large plateau of constant flow stress. The SHR of the new deformation stage is very weak, but after enormous shear strains of the order of $10^{3}$, the flow stress significantly increases above the plateau stress of Stage IV. If the authenticity and generality of the new stage is confirmed, it will offer the possibility of strengthening bulk materials by HPT to unforeseen levels.

- $\quad$ One plausible explanation (among others) for the ultra-SPD transition has been proposed in this paper: In Stage IV, the previous cellular and subgrain structure evolves to a near-exclusively grain structure of shrinking average size as deformation goes on. Inside the grains, the dislocation density is limited to the maximum value allowed in Stage IV as far as its crossing requires a curvature of the gliding dislocations larger than the average curvature of the encircling grain cross-section. Beyond that point, fully crossing the whole grain section requires a flow stress that exceeds the critical stress for cutting through the intragranular dislocation density unable to increase its value, i.e., the grain size takes control of the flow stress. In wire drawing, the reduction of the grain cross-section is very rapid and the SHR is very high; in HPT, the decline is very weak, and the SHR is very small.

Table 1 summarizes the approximate maximum (athermal) values of the saturation VME flow stress of single-phase polycrystals according to this paper.

Table 1. Approximate athermal values of the saturation VME flow stress and their associated determinant microstructural features of plastically deformed single-phase polycrystals.

\begin{tabular}{|c|c|c|c|}
\hline Stage & {$\left[\left(\sigma_{s}-\sigma_{0}\right) / G^{*}\right]_{T=0}$} & $\rho_{s}, \mathbf{m}^{-2}$ & Comments \\
\hline III & 0.015 & $10^{16}$ & \multirow{2}{*}{ Limited by max. disloc. density } \\
\hline IV & 0.024 & $2.6 \times 10^{16}$ & \\
\hline ultra-SPD & Probably $\leq 0.08$ & $2.6 \times 10^{16}$ & \multirow[b]{2}{*}{ Limited by sat. grain size, $D_{s} \approx 3 \mathrm{~nm}$} \\
\hline $\begin{array}{c}\text { bcc and hcp } \\
\text { wire-drawing }\end{array}$ & 0.08 & $2.6 \times 10^{16}$ & \\
\hline absolute ideal limit & 0.3 & $4 \times 10^{18}$ & Limited by amorphization \\
\hline
\end{tabular}




\section{Suggestions for Further Research Work}

Despite the big amount of research published on the topic of this paper, many open questions remain. Some very obvious among others are:

(a) The detailed mechanistic explanation of the recovery processes of Stage III responsible for the validity of the Voce stress-strain equation;

(b) The systematic study and characterization of the structural basis of Stage IV and its dependence of on temperature, strain rate, and SFE;

(c) Confirmation of the authenticity of the recently proposed ultra-SPD stage and study of its micromechanistic origin is, of course, crucial.

(d) If the authenticity of the new stage is confirmed, its full characterization will be an excellent research opportunity. The influence of chemical composition on this hardening transition should be indeed addressed; the influence of both purity and alloying also call for study. Similarly, the influence of the homologous deformation temperature, strain rate, and SFE on the emergence as well as the stability of the strength after the strains imparted would merit a the research effort.

Funding: This research received no external funding.

Acknowledgments: The author acknowledges Mikhail Lebyodkin for his kind invitation to write this paper. He also gratefully thanks George Langford for having generously shared his works with him since beginning the research. This paper is dedicated to him on occasion of the 50th anniversary of the publication, with Morris Cohen, of his famous and inspiring paper on iron wire drawn to large strains (ref. [58] of this paper).

Conflicts of Interest: The author declares no conflict of interest.

\section{References}

1. Basinski, S.J.; Basinski, Z.S. Plastic Deformation and Work Hardening. In Dislocations in Solids; Nabarro, F.R.N., Ed.; Amsterdam-Oxford: North Holland, The Netherlands, 1979; Volume 4, pp. 261-362.

2. Gil Sevillano, J. Flow Stress and Work Hardening. In Materials Science and Technology. A Comprehensive Treatment; Cahn, R.V., Haasen, P., Kramer, R.J., Mughrabi, H., Eds.; Plastic Deformation and Fracture of Materials; VCH: Weinheim, Germany, 1993; Volume 4.

3. Kocks, U.F.; Mecking, H. Physics and phenomenology of strain hardening: The FCC case. Prog. Mater. Sci. 2003, 48, 171-273. [CrossRef]

4. Kubin, L.P. Dislocations, Mesoscopic Simulations and Plastic Flow; Oxford Series on Materials Modelling; Oxford University Press: Oxford, UK, 2019.

5. Cordero, Z.C.; Knight, B.E.; Schuh, C.A. Six Decades of the Hall-Petch Effect-A Survey of Grain-Size Strengthening Studies on Pure Metals. Int. Mater. Rev. 2016, 61, 495-512. [CrossRef]

6. De las Cuevas, F.; Gil Sevillano, J. Effects of temperature and strain rate in strain hardening in torsion of a twinning-induced plasticity steel. Mater. Sci. Technol. 2019, 35, 669-679. [CrossRef]

7. Rohatgi, A.; Vecchio, K.S.; Gray, G.T., III. The influence of stacking fault energy on the mechanical behaviour of $\mathrm{Cu}$ and $\mathrm{Cu}-\mathrm{Al}$ alloys: Deformation twinning, work hardening and dynamic recovery. Metall. Mater. Trans. A 2001, 32, 135-145. [CrossRef]

8. Salem, A.A.; Kalidindi, S.R.; Doherty, R.D.; Semiatin, S.L. Strain hardening due to deformation twinning in alpha-titanium: Mechanisms. Metall. Mater. Trans. A 2006, 37, 259-268. [CrossRef]

9. Gil Sevillano, J.; Van Houtte, P.; Aernoudt, E. Large strain work hardening and textures. Prog. Mater. Sci. 1980, 25, 69-412. [CrossRef]

10. Backofen, W.A. Deformation Processing; Addison Wesley: Boston, MA, USA, 1972.

11. Alberdi Garitaonandia, J.M. Grandes Deformaciones Plásticas en Frío en Policristales de Cobre y Aluminio (torsión). Ph.D. Thesis, Faculty of Sciences, University of Navarra, San Sebastián, Spain, 1984.

12. Zehetbauer, M.; Seumer, V. Cold work hardening in stages IV and V in F.C.C. metals-I. Experiments and interpretation. Acta Metall. Mater. 1993, 41, 577-588. [CrossRef]

13. Rollett, A.D.; Kocks, U.F. A review of the stages of work hardening. In Dislocations 93; Rabier, J., George, A., Bréchet, Y., Kubin, L.P., Eds.; Solid State Phenomena; Trans Tech Publications Ltd.: Baech, Switzerland, 1993; Volume 35-36, pp. 1-18. 
14. Siethoff, H.; Schroeter, W.; Metallkunde, Z. New phenomena in the plasticity of semiconductors and FCC metals at high temperatures. I.-Theoretical Models. Z. Metallkd. 1984, 75, 475-481.

15. Aldazabal, J.; Alberdi, J.M.; Gil Sevillano, J. Stage IV: Microscopic or mesoscopic effect? In Nanomaterials by Severe Plastic Deformation: Proceedings of the Conference Nanomaterials by Severe Plastic Deformation-nanoSPD2, Vienna; Zehetbauer, M., Valiev, R.Z., Eds.; Wiley-VCH: Weinhein, Germany, 2004; pp. 65-71.

16. Kok, S.; Beaudoin, A.J.; Tortorelli, D.A. On the development of stage IV hardening using a model based on the mechanical threshold. Acta Mater. 2002, 50, 1653-1667. [CrossRef]

17. Estrin, Y.; Toth, L.S.; Molinari, A.; Bréchet, Y. A dislocation-based model for all hardening stages in large strain deformation. Acta Mater. 1998, 46, 5509-5522. [CrossRef]

18. Gil Sevillano, J.; Matey Muñoz, L.; Flaquer Fuster, J. Ciels de Van Gogh et propriétés mécaniques. J. Phys. IV 1998, 8, Pr4-Pr155-Pr4-Pr165. [CrossRef]

19. Gil Sevillano, J.; González, D.; Martínez-Esnaola, J.M. Heterogeneous deformation and internal stresses developed in BCC wires by axisymmetric elongation. Mater. Sci. Forum 2007, 550, 75-84. [CrossRef]

20. Young, C.M.; Anderson, L.J.; Sherby, O.D. On the steady state flow stress of iron at low temperature and large strains. Metall. Trans. 1974, 5, 519-520. [CrossRef]

21. Gil Sevillano, J. On the limits of strain hardening by plastic deformation. In Proceeding International Symposium on Plastic Deformation and Texture Analysis Alcoy (Spain) 2012; Amigó Borrás, V., Ed.; Editorial Universitat Politècnica de València: Valencia, Spain, 2012; pp. 1-15.

22. Gil Sevillano, J.; Aldazabal, J.; Aldazabal, I. Elasto-plastic behaviour of a columnar structure of nanocrystalline iron with sharp «011 > texture. Materialia 2018, 2, 218-230.

23. Segal, V.M. Invention Certificate of the USSR, No. 575,892 (1977) and Methods of investigation of strain-deformed state in processes of plastic change of shape. Ph.D. Thesis, Physico-Technical Institute of Acad. Sci. of Belorus, SSR, Minsk, Russia, 1974.

24. Segal, V.M.; Reznikov, V.I.; Drobyshevkij, A.E.; Kopylov, V.I. Plastic treatment of metals by plastic shear. Russ. Metall. 1981, 1, 115-123.

25. Valiev, R.Z.; Kaibyshev, O.A.; Kuznetsov, R.I.; Musalimov, R.S.; Tsenev, N.K. Low-temperature superplasticity of metallic materials. Dokl. Akad. Nauk. SSSR 1988, 301, 864-866.

26. Valiev, R.Z.; Krasilnikov, N.A.; Tsenev, N.K. Plastic deformation of alloys with submicron-grained structure. Mater. Sci. Eng. A 1991, 137, 35. [CrossRef]

27. Valiev, R.Z.; Islamgaliev, R.K.; Alexandrov, I.V. Bulk nanostructured materials from severe plastic deformation. Prog. Mater. Sci. 2000, 45, 103-189. [CrossRef]

28. Valiev, R.Z.; Langdon, T.G. Principles of equal-channel angular pressing as a processing tool for grain refinement. Prog. Mater. Sci. 2006, 51, 881-981. [CrossRef]

29. Estrin, Y.; Vinogradov, A. Extreme grain refinement by severe plastic deformation: A wealth of challenging results. Acta Mater. 2013, 61, 782-817. [CrossRef]

30. Dalla Torre, F.H.; Pereloma, E.V.; Davies, C.H.J. Strain hardening behaviour and deformation kinetics of $\mathrm{Cu}$ deformed by equal channel angular extrusion from 1 to 16 passes. Acta Mater. 2006, 54, 1135-1146. [CrossRef]

31. Figueiredo, R.B.; Langdon, T.G. The development of superplastic ductilities and microstructural homogeneity in a magnesium ZK60 alloy processed by ECAP. Mater. Sci. Eng. A 2006, 430, 151-156. [CrossRef]

32. Vinogradov, A.; Suzuki, T.; Hashimoto, S.; Kitagawa, K.; Kuznetsov, A.; Dobatkin, S. Structure and mechanical properties of submicrocrystalline copper produced by ECAP to very high strains. Mater. Sci. Forum 2006, 503-504, 971-976. [CrossRef]

33. Wang, Y.L.; Lapovok, R.; Wang, J.T.; Qi, Y.S.; Estrin, Y. Thermal behaviour of copper processed by ECAP with and without back pressure. Mater. Sci. Eng. A 2015, 628, 21-29. [CrossRef]

34. Valiev, R.Z.; Alexandrov, I.V.; Zhu, Y.T.; Lowe, T.C. Paradox of strength and ductility in metals processed by severe plastic deformation. J. Mater. Res. 2002, 17, 5-8. [CrossRef]

35. Mishra, A.; Kad, B.K.; Gregori, F.; Meyers, M.A. Microstructural evolution in copper subjected to severe plastic deformation: Experiments and analysis. Acta Mater. 2007, 55, 13-28. [CrossRef]

36. Kulczyk, M.; Pachla, W.; Swiderska-Sroda, A.; Krasilnikov, N.; Diduszko, R.; Mazur, S.A.; Lojkowski, W.; Kurzydlowski, K.J. Combination of ECAP and Hydrostatic Extrusion for UFG Microstructure Generation in Nickel. Solid State Phenom. 2006, 114, 51-56. [CrossRef] 
37. Zhilyaev, A.P.; Nurismalova, G.V.; Baró, M.; Valiev, R.Z.; Langdon, T.G. Thermal stability and microstructural evolution in ultra-fined nickel after equal-channel angular pressing (ECAP). Metall. Mater. Trans. A 2002, 33, 1865-1868. [CrossRef]

38. Raju, K.M.; Krishna, M.G.; Padmanabhan, K.A.; Muraleedharan, K.; Gurao, N.P.; Wilde, G. Grain size and grain boundary character disribution in ultra-fine grained (ECAP) nickel. Mater. Sci. Eng. A 2008, 491, 1-7. [CrossRef]

39. Liu, F.; Yuan, H.; Goel, S.; Liu, Y.; Wang, J.T. Bulk nanolaminated nickel: Preparation, microstructure, mechanical property, and thermal stability. Metall. Mater. Trans. A 2017, 49, 576-594. [CrossRef]

40. Muñoz Bolaños, J.A.; Higuera Cobos, O.F.; Cabrera Marrero, J.M. Strain hardening behavior of ARMCO iron processed by ECAP. IOP Conf. Ser. Mater. Sci. Eng. 2014, 63, 1-8.

41. Muñoz, J.A.; Higuera, O.F.; Cabrera, J.M. Microstructural and mechanical study in the plastic zone of ARMCO Iron processed by ECAP. Mater. Sci. Eng. 2017, 697, 24-36. [CrossRef]

42. Han, B.Q.; Lavernia, E.J.; Mohamed, F.A. Dislocation structure and deformation in iron processed by equal-channel-angular pressing. Metall. Mater. Trans. A 2004, 35, 1343-1350. [CrossRef]

43. Segal, V.M.; Reznikov, V.I.; Kopylov, V.I.; Pavlik, D.A.; Malyshev, V.F. Protsessy Plasticheskogo Strukturoobrazovaniya Metallov; Nauka i Tekhnika: Minsk, Russia, 1994; p. 232.

44. Sus-Ryszkowska, M.; Wejrzanowski, T.; Pakieła, Z.; Kurzydłowski, K.J. Microstructure of ECAP severely deformed iron and its mechanical properties. Mater. Sci. Eng. 2004, 369, 151-156. [CrossRef]

45. Vinogradov, A.Y.; Stolyarov, V.V.; Hashimoto, S.; Valiev, R.Z. Cyclic behavior of ultrafine-grain titanium produced by severe plastic deformation. Mater. Sci. Eng. A. 2001, 318, 163-173. [CrossRef]

46. Zhao, X.; Fu, W.; Yang, X.; Langdon, T.G. Microstructure and properties of pure titanium processed by equal-channel angular pressing at room temperature. Scr. Mater. 2008, 59, 542-545. [CrossRef]

47. Bridgman, P.W. Studies in Large Plastic Flow and Fracture. With Special Emphasis on the Effects of Hydrostatic Pressure; Harvard Univ. Press: Cambridge, MA, USA, 1952.

48. Edalati, K.; Horita, Z. A Review on High-Pressure Torsion (HPT) from 1935 to 1988. Mater. Sci. Eng. A 2016, 652, 325-352. [CrossRef]

49. Erbel, S. Mechanizm Zmian Własności Metali Poddanych Wielkim Odkształceniom; Wydawnictwa PW: Warszawa, Poland, 1976.

50. Bryla, K.; Edalati, K. Historical studies by Polish scientist on ultrafine-grained materials by severe plastic deformation. Mater. Trans. 2019, 60, 1553-1560. [CrossRef]

51. Pippan, R.; Wetscher, F.; Hafok, M.; Vorhauer, A.; Zhyliaev, I.S. The limits of refinement by severe plastic deformation, the limits of refinement by plastic deformation. Adv. Eng. Mater. 2006, 8, 1046-1056. [CrossRef]

52. Zhyliaev, A.P.; Langdon, T.G. Using high-pressure torsion for metal processing: Fundamentals and applications. Prog. Mater. Sci. 2008, 53, 893-979. [CrossRef]

53. Starink, M.J.; Cheng, X.; Yang, S. Hardening of pure metals by high-pressure torsion: A physically based model employing volume-averaged defect evolutions. Acta Mater. 2013, 61, 183-192. [CrossRef]

54. Kawasaki, M. Different models of hardness evolution in ultrafine-grained materials processed by high-pressure torsion. J. Mater. Sci. 2013, 49, 18-34. [CrossRef]

55. Balasubramanian, N.; Langdon, T.G. The strength-grain size relationship in ultrafine-grained metals. Metall. Mater. Trans A 2017, 47,5827-5838. [CrossRef]

56. Edalati, K. Metallurgical Alchemy by ultra-severe plastic deformation via high-pressure torsion process. Mater. Trans. 2019, 60, 1221-1229. [CrossRef]

57. Edalati, K.; Cubero-Sesin, J.M.; Alhamidi, A.; Mohamed, I.F.; Horita, Z. Influence of severe plastic deformation at cryogenic temperature on grain refinement and softening of pure metals: Investigation using high-pressure torsion. Mater. Sci. Eng. A 2014, 613, 103-110. [CrossRef]

58. Langford, G.; Cohen, M. Strain hardening of iron by severe plastic deformation. Trans. ASM 1969, 62, 623-638.

59. Pippan, R.; Scheriau, S.; Taylor, A.; Hafok, M.; Hohenwarter, A.; Bachmaier, A. Saturation of fragmentation during severe plastic deformation. Annu. Rev. Mater. Res. 2010, 40, 319-343. [CrossRef]

60. Edalati, K.; Horita, Z. High-pressure torsion of pure metals: Influence of atomic bond parameters and stacking fault energy on grain size and correlation with hardness. Acta Mater. 2011, 59, 6831-6836. [CrossRef]

61. Edalati, K.; Horita, Z. Significance of homologous temperature in softening behavior and grain size of pure metals processed by high-pressure torsion, Mater. Sci. Eng. 2011, 528, 7514-7523. [CrossRef] 
62. Edalati, K.; Akama, D.; Nishio, A.; Lee, S.; Yonenaga, Y.; Cubero-Sesin, J.M.; Horita, Z. Influence of dislocation-solute atom interactions and stacking fault energy on grain size of single-phase alloys after severe plastic deformation using high-pressure torsion. Acta Mater. 2014, 69, 68-77. [CrossRef]

63. Gil Sevillano, J.; Aldazabal, I.; Luque, A.; Aldazabal, J. Atomistic simulation of the elongation response of a $\langle 011\rangle$ oriented columnar nano-grain bcc Fe polycrystalline sample. Meccanica 2016, 51, 401-413. [CrossRef]

64. Langford, G.; Cohen, M. Calculation of cell-size strengthening of wire-drawn iron. Metall. Trans. 1970, 1, 1478-1480. [CrossRef]

65. Biswas, C.P. Strain Hardening of Titanium by Severe Plastic Deformation. Ph.D. Thesis, Massachusetts Institute of Tecnology, Cambridge, MA, USA, 1973.

66. Edalati, K.; Horita, Z.; Fujiwara, H.; Ameyama, K. Cold consolidation of ball-milled titanium powders using high-pressure torsion. Metall. Mater. Trans. A 2010, 41, 3308-3317. [CrossRef]

67. Rack, H.J.; Cohen, M. Strain hardening of iron-titanium alloys at very large strains. Mater. Sci. Eng. 1970, 6, 320-326. [CrossRef]

68. Hosokawa, A.; Ii, S.; Tsuchiya, K. Work hardening and microstructural development during high-pressure torsion in pure iron. Mater. Trans. 2014, 55, 1097-1103. [CrossRef]

69. Mehta, S.; Varma, S.K. Structure-sensitive properties during room-temperature wire drawing at various speeds in nickel 200. J. Mater. Sci. 1992, 27, 3570-3574. [CrossRef]

70. Nuttall, J.; Nutting, J. Structure and properties of heavily cold-worked fcc metals and alloys. Metal Sci. 1978, 12, 430-438. [CrossRef]

71. Zimmer, W.H.; Hecker, S.S.; Rohr, D.L.; Murr, L.E. Large strain plastic deformation of commercially pure nickel. Met. Sci. 1983, 17, 198-208. [CrossRef]

72. Zepeda-Ruiz, L.A.; Stukowski, A.; Oppelstrup, T.; Bulatov, V.V. Probing the limits of metal plasticity with molecular dynamics simulations. Nature 2017, 550, 492-495. [CrossRef]

73. Frost, H.J.; Ashby, M.F. Deformation Mechanism Maps: The Plasticity and Creep of Metals and Ceramics; Pergamon Press: Oxford, UK, 1982.

(C) 2020 by the author. Licensee MDPI, Basel, Switzerland. This article is an open access article distributed under the terms and conditions of the Creative Commons Attribution (CC BY) license (http://creativecommons.org/licenses/by/4.0/). 